\title{
Comprehensive reform and Practice of Environmental Engineering specialty which based on professional certification
}

\author{
Ding Cheng \\ Yancheng Institute of technology \\ School of environmental science and engineering \\ Jiangsu, Yancheng, China \\ ycdingc@163.com
}

\author{
Yang Bairen \\ Yancheng Institute of technology \\ School of environmental science and engineering \\ Jiangsu, Yancheng, China \\ ybairen@163.com
}

\begin{abstract}
In accordance with the requirements of professional certification, the comprehensive reform of environmental engineering is committed to improve the overall level of talent training, and carry out the outstand engineering practical ability training, which through the training mode of creative talents, strengthening teaching teams, optimizing curriculum system, perfecting the practical teaching system and reconstruction of the teaching management system.
\end{abstract}

keywords-Professional certification; engineering practical ability; creative ability; talent training mode; comprehensive reform of the specialty

\section{INTRODUETION}

As a quality guarantee of higher education, professional certification first appeared in the United States [1]. Professional construction and development are the foundation of operating schools which professional levels directly affect the overall level of school-running. Good professional certification could give full play to its unique features, deepening the teaching reform of school, improving the teaching quality, educational level and running benefits. So the school can take full advantage and have its characteristic [2].

Environmental engineering specialty in Yancheng Institute of technology school is the professional for key construction to meet the environmental industry development and to coordinate national strategies for coastal development. In 2012, this program was selected as the "Twelve-Five" key specialty of colleges and universities in Jiangsu Province; for the professional needs of the construction and development, combined with the guiding spirit of professional certification, the reform and practice outstanding engineering practical ability training of environmental engineering was integrated.

\section{COMPREHENSIVE REFORM}

In reference both at home and abroad engineering teaching reform experience and summary based on the existing environment engineering professional experience, combined environment engineering professional of features and school running features, to optimization talent training programme for hand, advance "1+3" talent training mode reform; to upgrade teachers engineering background for focus, foster based on "courses group" of professional teaching team; carried out "case teaching" and "simulation type teaching", formed "interactive" teaching features; to improved practice teaching conditions for focus, Perfecting the practical teaching ability as a main line system; improve effective management system and operation mechanism.

\section{CONCRETE MEASURES FOR REFORM}

\section{A. To optimize the talent training plan as the starting point,} push" $1+3$ " talents training mode reform

" 1 ", the advantage of cultivating talents in colleges and universities, is the basis of environmental engineering of training applied innovative talents platform.

Through this platform, students will have prerequisite knowledge structure and ability structure for engineering in environmental evaluation, design and management. " 3 ", which is the way of talent cultivation, and the basic characteristic of training applied innovative talents for environmental engineering, includes combining common culture with personality cultivation, combining School training with enterprise culture, and Combining academic with vocational education.

Combining common culture with personality cultivation will not only equip students with environmental industries engineering practice ability and quality, but also equip students with cross- disciplines or cross - professional basic knowledge and basic skills adapting to engaged in environmental work in a variety of industries.

Combining School training with enterprise culture will not only equip students with specialized theoretical knowledge and practical skills in environmental engineering, but also equip students, who directly engaged in the professional, with engineering practical ability and innovative consciousness on the line of industry - oriented enterprises.

Combining academic with vocational education, that is to Make Students receive quality training and skill basic training on Registered EIA engineer, certified environmental engineers and other types of registered engineers in accordance with the knowledge and ability requirements for registered engineersof Professional qualification system of environmental protection 
industry, to improve the comprehensive competitive power of talents[3,4].

" $1+3$ " Talents Training Mode Reform, which is the way around the professional features on diversity of environmental engineering talents training standards, Professional Curriculum System, and the open of specialty construction, make full use of existing teaching conditions, pay attention to broad - gauge, three - dimensional multi-directional, cultivate talents. Specific reform plan include :

$i$ According to the characteristics of Environmental Engineering Course practice, its strongly applied characteristic, the ability of students of learning, innovation, practical, Communication and social adaptation will be enhanced, and professional personnel cultivation project will be optimized. "modular" Curriculum System, additional innovation credit, and Strengthening Practical Teaching links, will be included in the practice of the teaching plan, Total credits adjusted to account for Students (class hours) 35, Meanwhile, the total number of controls between 170-180.

ii Cultivation of Students' adaptation to the needs of a variety of industries engaged in environmental protection work; Strengthening interdisciplinary,, professional basic knowledge and basic skills training; combining ecological environmental protection and environmental protection industry in Yancheng of Jiangsu seabeach development; Wide caliber, personalized training professionals by making use of machinery, marine and civil engineering discipline advantage in the school.

iii Improving the professional ability of student in environmental engineering in the future; Strengthening students' basic quality training and skills development, such as registered Engineer, certified environmental engineer environmental impact assessment and other types of environmental registers engineer; increasing the targeted teaching content of theoretical Courses and practical steps.

iv Enterprises involved in the cultivation of professional talents to Strengthen the depth of fusion between schools and enterprises. School - enterprise cooperation and development of corporate training programmes practiced according to the characteristics of environmental protection industry, business needs and Talent Cultivation Objective orientation. " double teacher " is implemented by Equipping student with a business mentor and school teachers respectively in the scale of 10:1.

The intelligence, which is obtained by Environmental engineering speciality teachers in innovation enterprises "kyd, Jiangsu Province Science and Technology Ltd" set up in Yancheng Institute of Technology University of Science and Technology Park, in environmental engineering design, environmental impact assessment, and Pollution management and operation of the facility, is made use of to provid adequate Engineering practice resources for students[5].

\section{B. To enhance teachers' focus on the engineering background, and cultivate the professional teaching team based on the "Course group"}

Teachers team construction of environmental engineering specialty will pay more attention to improve the engineering background in addition to improving the educational level of teachers. Professional team of teachers cultivation not only needs a reasonable age structure of the title, but also requires experience in engineering practice.
Construction of professional teaching team specific programmes include :

$i$ Implementation of the " Famous works " to enhance the teaching and scientific research level of professional teaching force. Improving the educational level of teachers through the introduction, the Committee, study methods, adhering to the attachment system of professional teachers, and cultivating engineering practice " teacher " with high level of scientific research and teaching. Specific measures include :

Teachers with shortage of engineering experience will learn exchanges to the field of environmental engineering and related industries in the form of on-the-job, be familiar with and master the entire business processes, and strengthen practical skill. Encouraging teachers to focus on solving actual problems of industry and enterprise to develop scientific research and technology services; Mastering the development trend of environmental protection industry and the latest cutting edge of technology; Proactively inviting industry experts to carry out academic lectures, and employing wellknown experts as consultants or Adjunct Professors to upgrade the Professional Teachers' teaching ability in scientific research.

ii executing " double teacher cultivation project ", creating and connecting with the teaching team. Requirements for teachers' teaching team: the ability of the theory for professional; technical practice ability and qualifications for teachers; and engineer qualifications. Execution of " double teacher cultivation project " focused on Enhancing teaching part-time tutor guidance capability through training, observing and learning, and on Enhancing teacher's ability of in engineering practice by focusing on such qualification examination as National Registered EIA engineer, Safety Evaluation of registered engineers, the State Environmental Protection Department issued the " Cleaner Production auditor ", environmental assessment certificate, water treatment facility operating licence.

iii To build a team of excellent teaching with demonstration effect around the " courses " building. To build an excellent teaching team with a demonstration effect around the curriculum Group construction, of " environmental impact assessment " and " environmental engineering design and operation ". Excellent teaching team focuses not only on Reasonable collocation of age, education level, but also on rich experience in engineering practice, good operation mechanism, supervision and restraint mechanism and Management mode.

\section{To develop " case teaching " and "type of simulation teaching method ", to formate teaching characteristic of " interactive".}

Continuing to adhere to the " Student - Centered " teaching philosophy; Paying attention to stimulate students interest in learning and fostering ability of autonomous learning; making a further change on the traditional teaching method "centered on teaching"; and actively promoting the " teaching " and " learning " Interactive Teaching Mode.

According to present situation of environmental engineering course practice, its applied characteristic is strong and Engineering Education is in the lack of comprehensive training for actual production; The "Case Method of Teaching" and "Simulation Teaching" should be promoted to 
realize "Interaction of teaching and practice", "Interaction between Teaching and Scientific Research Practice", "Interaction between teachers and students" and "Student student interaction ".

Meanwhile, modern educational technology should be made full use of, network learning platform should be constructed, professional foundation course and specialized course curriculum website should be constructed by using "Sky Room" network platform to break through " teaching " and " learning " time and space restrictions.

i "Case Teaching",based on the environmental engineering specialty course with strong practicality and application[6,7],

include Policies on environmental, economic and related legal knowledge, Such as the Environmental Planning, the environmental law, environmental economics and so on. The " Case Teaching Method " should be carried out to improve students' interests, from passive to active. Actively seeking and preparing suitable and representative and typical cases, and Take the supplement, the teacher guides the students to discuss the Teaching Mode after summarize, to improve teachers' perfonnance.

ii "Simulation teaching". Breakthroughs for the actual production of integrated training deficiencies and lack of funds brought experimental teaching equipment sets limits of bottleneck, using "simulation teaching", enable students to master the systematic control of the whole production process technology, especially under contrived conditions repeatedly start and stop, characteristics of technology, technology and equipment fault handling and other operations, effect of supplementing and expanding laboratory comprehensive experimental teaching, and so on. Focuses on the development of the "three wastes" pollution control simulation teaching software engineering courses, so that students "simulation" mode, deepen awareness of environmental health engineering process, as well as timely disposal of process failures in the operation to adapt to environmental engineering from extensive to intensive development trend $[8,9]$.

iii Reform of examination method of teaching method reform and teaching characteristics. To study students of practice hands-on capacity for Center, reform existing of exam system, implemented "test" and "taught" separation, improve survey report, and experiment internship report, and courses papers, and case analysis, and literature reviewed, and experiment operation, and skills demonstrates, and said class, and simulation try taught, assessment way in evaluation students learning results in the of role, and to assessment way of reform promote teaching way of improved.

\section{With a focus on improving practical teaching conditions, improve ability as a main line of the practice teaching system.}

Environmental engineering practice teaching system is the framework for the cultivation of engineering ability and creativity as the main line, reflects the practice of teaching goals, content and the relationship between the teaching conditions.

Practice teaching main is through "five a platform" support whole practice teaching system, this which practice teaching platform, and engineering training center and school enterprises cooperation platform is hardware platform, engineering background teachers and practice teaching management is software platform; teaching content through hidden courses and dominant courses of mutual role to achieved, which "three level" is hidden courses content, including courses social practice activities, and levels subject race and students practice innovation activities, "four module" is followed by progressive of dominant courses module, Including courses experiment and design, and school within engineering real training, and enterprise engineering practice and engineering integrated practice; "II elements" is practice teaching of target, that: is training students of pass General capacity and literacy, and professional capacity and quality; "a mainline" is engineering education of mainline, that training students of engineering practice capacity and innovation spirit, practice teaching system of framework is around this mainline expand.

$i$ In accordance with the overall planning of school laboratories, strengthening the construction of laboratory. Adhere to the teaching, integration of teaching, scientific research and laboratory construction, increase the input of laboratory construction. In hardware, further enhancing the overall level of laboratory, laboratory area increased to 2000 $\mathrm{m}^{2}$, total assets reached 12 million Yuan. Laboratories through the national measurement accreditation, which satisfies the General laboratory needs of the students, meet the needs of innovative experiments and scientific research work of University students.

ii Strengthen the construction of engineering training base in school. The construction "East Campus laboratory wastewater treatment system", is scheduled to start in 2012 around 2 million Yuan building, after the project is completed, will achieve environmental college students within the school of engineering training with the objective. Environmental Sciences founded by teachers in University Science Park ecobusiness-oriented environmental engineering students with environmental assessment, environmental planning and environmental engineering design practice, training, school engineering training base.

iii Construction of practice bases. Aimed primarily at domestic environmental protection enterprises, high-tech companies, seeking partnership with them to build student internship, training center, environmental engineering student internships, training requirements, for example, collaboration with the Jiangsu branch of environmental engineering limited, a "Center for environmental engineering practice."

iv Hierarchical, modular, practical courses. Make integration of the practical course, modular courses, and hierarchical hidden curriculum, reflects the practical course system to train the ability of engineering practice-oriented. Module of dominant courses, is included teaching plans of all practice class courses, including experiment courses are integration to courses experiment and design, and school within engineering real training, and Enterprise engineering practice and engineering integrated practice, 5 a module, according to progressive relationship and manpower arrangements teaching plans; level of hidden courses, is no included teaching plans of practice activities into social practice, and subject race and students practice innovation activities three a level, and into practice teaching system, full play hidden courses on students integrated practice capacity training of role. 
$\mathrm{v}$ Innovation practice teaching model. Experiment with an emphasis on experiments, gradually reducing verifies experiment; Course design in conjunction with environmental engineering case to progressively increase the engineer basic quality cultivating; Enterprise practice links to cultivate practical skills and learn advanced technology as the goal, pay attention to the combination of practice and practice, improve students ' basic skills; Engineering practice of "cooperation between schools and enterprises, platform sharing, project lead" teaching model, around issues of practical, integrated practice.

\section{E. Management system and operational mechanism of effective teaching}

"Prominent people-oriented, outstanding teacher's leading and student's subject status" as a starting point, "teachers and students to participate in the management, teaching, learning and managing third-party checks and balances mechanism" established targets and teaching management, promote the modernization of management thought and management methods, establish an effective management system and operating mechanism.

Implementation human teaching management of strategy, achieved teaching management full subject of, and teaching management method professional and scientific, and teaching management process human and quality management full of; focused on using effective incentive mechanism, mobilization General teachers and students of enthusiasm and consciousness, from essentially improve teaching management of effectiveness; full using modern information technology means, built network teaching management platform, further perfect management information system, formed has advanced, and can operation sex of modern teaching information service system and Senate integrated management system, Run teaching network and teaching management informationization.

In addition, in accordance with environmental engineering applied innovative talents cultivation system, reform will also focus on perfecting teaching management system and operational mechanism to guarantee the realization of reforms, including improving the teaching of basic management system, ISO9002 established total quality management philosophy of teaching quality supervision and guarantee system, structuring the graduates' employment situation of feedback mechanisms, and so on.

\section{CONCLUSION}

Professional certification is an important opportunity for engineering education development and the direction. In order to ensure the implementation of professional certification, integrated reform must be carried on for environment engineering professional. According to the professional certification requirements, the reform innovate talent-training model, strengthening teaching teams, optimizing curriculum system, perfecting the practical teaching system and reconstruction of the teaching management system, improving the overall level of talent. So the environmental engineering building will reflect local characteristics, industry characteristics and school characteristics. It also can provide the Guide and demonstration for reform of environmental engineering specialty in local engineering colleges.

\section{REFERENCES}

[1] Yang Zhenhong, Yang Shuhong, Song Shouxin, etc. foreign engineering education (undergraduate) professional certification analysis and reference of [J]. China Security journal, 2009,19 (2): 61-66.

[2] Jia Conglin. Ideas and experiences of engineering education accreditation in China [J]. Computer education, 2009 (3): 34-39.

[3] Jian Lin. Excellence in engineering education-oriented nature, creative engineering talents training mode [J]. higher education in China, 2011 (6): 19-21.

[4] Wang Hong. Updated training concept, training mode of creative talents $[\mathrm{J}]$. Shanghai University of engineering and technology education research 2010 (3): 1-4.

[5] Chang Yunlong, Li rongde, Yuan Xiaoguang, et al. enhanced ability of engineering practice and innovation ability training materials-Shenyang University of technology forming and controlling engineering innovation and practice[J]. Higher engineering education research, 2011 (4): 101-103.

[6] Lu Yuan. Characteristics and applicability analysis of the nature of case method [J]. vocational and technical education, 2007,284 (28): 22-24.

[7] Guo Yuqing. General education courses in environmental and ecological sciences discussion on the rationality of the implementation of case teaching in China [J]. theory and practice of education, 2010,30 (1): 5253.

[8] Zou Zhuying, Peng Wenwu, Luo Qinghai, et al. Analysis of application of simulation teaching method in engineering education [J]. Journal of Hengyang normal College, 2012,33 (1): 146-149.

[9] Wang, Fang ling, Liu Zuwen, et al. application of simulation teaching method in the teaching of sewage treatment[J]. Journal of Jiangxi University, 2009,30 (4): 87-88. 